\title{
Student's modernist socio - political attitudes and Sensation seeking (The case of study: Isfahan University's students)
}

\author{
Hamid Dehghani ${ }^{1}$, Seyyed Alli Hashemianfar ${ }^{2}$, Maghsood Farasatkhah ${ }^{3}$ \\ ${ }^{1} \mathrm{PhD}$ candidate of sociology, University of Isfahan, Isfahan, Iran \\ ${ }^{2}$ Assistante professor with the sociology department, University of Isfahan, Isfahan, Iran \\ ${ }^{3}$ Associate professor, Institue for Research \& planning in Higher Education (IRPHE), Tehran, Iran
}

\begin{abstract}
Attitudes are important role on the people's life. This paper examines how student's modernist sociopolitical attitudes may be influenced by their sensation seeking and socioeconomic status. This study performed by using survey method. The population of study consisted of all Isfahan University's students. A number of 360 students were selected as the participants using quota sampling method. Data analysis was done using SPSS and Amos software. The results showed that the mean score of modernist sociopolitical attitudes among students was above average. The result of a two-variate regression shows that there is a positive relationship between the two independent variables (sensation seeking and sociopolitical status) and student's modernist sociopolitical attitudes. In the other words, as the amount of sensation seeking and socioeconomic status increase, the amount of modernist attitudes among the students also increases. The result of multivariate analysis shows that there is significant correlation between sensation seeking and student's modernist sociopolitical attitudes. The correlation obtained a Beta standardized coefficient of 0.32 with $($ sig $=000)$. The value of $R$ square shows that independent variables account for 0/11 of changes in student's modernist sociopolitical attitudes. The result of the fit indices of the structural equation modeling shows that, the model has goodness of fit. Model fit indices such as CMIN/DF ratio, IFI, NFI, CFI, PCFI, RMSEA, were inspected. The fit indices indicate that the collected data well confirmed the developed model.
\end{abstract}

Keywords: Modernist sociopolitical attitudes, sensation seeking, socioeconomic status, students, education.

\section{Introduction and statement of the problem}

Attitude refers to a positive or negative orientation towards an object, a person, a particular group of people. The attitude construct continues to be a major focus of theory and research in the social and behavioral sciences. There is general agreement that attitude represents a summary evaluation of a psychological object captured in such attribute dimensions as good-bad, harmful-beneficial, pleasant-unpleasant, and likabledislikable (Ajzen, 2001: 28). This paper examines how student's modernist sociopolitical attitudes may be influenced by their sensation seeking and socioeconomic status. The question is to what extent are people's attitudes related to their personality. The major issue to be discussed here is whether or not attitudes have systematic and close relationship to personality traits such a sensation seeking. One of the best known of all attitudes studies is, The authoritarian personality that links attitudes to personality (Adorno, et al. 1950). The research results showed that highly prejudiced individuals were found to have rigid personality characteristics; they were highly conventional in values and standards; they rejected any negative implications about themselves or their parents; and projected socially unacceptable impulses or characteristics onto other people (Adorno, et al. 1950). Martin and Westie (1959) also studied on this subject, their results also showed clear connections between attitudes and personality traits. Conservative ideology has been studied by Tetlock (1983). He classified his sample population as liberal, moderate, or conservative. The findings showed that conservative people were significantly less complex in their thinking than were their liberal or moderate people: low complexity of thought, unusually positive ingroup attitudes. And negative affect toward outgroups. Baumeister and Finkel (2010) says that as attitude-relevant knowledge can vary in affective, cognitive, or behavioral content, it can be driven by the nature of the object, personality traits, culture, and social context. Most theorists agreed that attitudes are represented in memory as a part of person's knowledge structure. That is, they consist of associated networks of interconnected beliefs and evaluations. However, there is an alternative viewpoint that attitudes are largely constructed at any given point in time, based on other information (e.g., past experience, current mood, surroundings) that is currently salient and thus is easily called to mind (Oskamp and Schultz, 2005:9). Despite various studies on attitudes in Iran, no attention has been paid to periodic survey of student's attitudes and sensation seeking. The present study first presents a theoretical discussion on modernist sociopolitical attitudes. Then the specific analytical model of the study would be presented. In this regard, the 
present study primarily aims to examine the role of sensation seeking on student's modernist sociopolitical attitudes. Besides this primary goal, the study also pursues the following goals:

- Investigating modernist sociopolitical attitudes and its dimensions among Isfahan University's students.

- Investigating the amount of sensation seeking among Isfahan University's students.

- Investigating the socioeconomic status of Isfahan University's students.

\section{2-1-Introduction}

\section{Theoretical framework}

There are several main theoretical viewpoints about the essential nature of attitudes. One of these, called the tri componential viewpoint, holds that an attitude is a single entity but that has three aspects or components: affective, behavioral, and cognitive. An effective (emotional) component refers to the feeling and emotions one has toward the object. A behavioral component, consisting of one's action tendencies toward the object. A cognitive component, consisting of the ideas and beliefs that one has about the attitude object (Oskamp and Schultz, 2005:9).

Attitude theorists have long postulated that people hold attitudes because they can serve many useful functions. Various theorists proposed somewhat different, but often overlapping functions for attitudes. However, functions that have received the most attention include the knowledge function (i.e., the management and simplification of information processing tasks), utilitarian function (i. e., the achievement of desired goals and avoidance of negative outcomes), ego defensive function (i.e., the maintenance or promotion of selfesteem), the value expressive function (i.e., the expression of values and the self concept), and the social adjustive function (i,e., the facilitation of identification with similar others and the maintenance of relationships with them (Baumeister and Finkel, 2010:181).Thus, by this introduction to the attitude we go through investigating modernist sociopolitical attitudes.

\section{2-2- Modernist socio-political attitudes}

People's worldviews are important: they clearly affect the way people think and behave, at the personal, social and societal level. Insights into the nature of people's sociopolitical orientation. Sociopolitical attitudes refer to a general ideological tendency based on attitudes and beliefs about sociopolitical issues (Hastie, 2007: 259). In this paper sociopolitical attitudes based on four dimensions include; democratic attitudes, liberalism, critical thinking and individualism. Before all, we examine each dimension.

\section{2-2-1- Democratic attitudes}

Above all, democracy rather than being a way to govern is a way to live. Thus, to have a democratic government, we need a democratic community, and to have democratic community we need a democratic personality. Alexander (2006) believes to form a democracy we need special motives which are counter codes to nondemocratic ones. As he put it, democracy depends on self control and individual initiatives, the people who compose it are describe as being capable of activism and autonomy rather than as being passive and dependent. They are seen as rational and reasonable rather than irrational and hysterical, as calm rather than excited, as controlled rather than passionate, as sane and realistic rather than fantastical or mad (Alexander, 2006: 57). One type of approach to the culture and psychology of democracy is on the insights of psychoanalysis. Harold Lasswell has gone furthest in specifying the personality characteristic of the "democrat." In his list of democratic character qualities he includes (1) an "open ego," by which he means a warm and inclusive attitude toward other human beings; (2) a capacity for sharing values with others; (3) a multivalued rather than a singlevalued orientation; (4) trust and confidence in the human environment, and (5) relative freedom from anxiety (Almond and Verba, 1989: 10).

\section{2-2-2- Liberalism}

Democracy is more than voting; it also entails public discussion and debate. That in turn requires freedom of political expression. If the members of a demos are prevented from either expressing hearing certain views on public matters, their autonomy as democratic decision makers is impaired (Barry Clarke and Foweraker, 2001: 364). However, people should enjoy these freedoms as equal freedoms. Democracy requires not merely that people should have the right to participate but that they should have the right to participate equally, so that the freedoms that are essential to the functioning of democracy are freedoms that democratic citizens should enjoy equally (Barry Clarke and Foweraker, 2001: 364). In Hegel's thought also, human determination is freedom. For Hegel freedom is neither a faculty given by nature nor a capacity of the self, but rather is a structure of interaction between individuals where in the self-determination of each is constitutively related to that of others through mutual recognition and respect (Luther, 2009: 119). For Hegel, each individual's identity as a free person depends on the rational unity of the whole. And also the most important discussion of 
liberalism is its emphasis on the equality of woman and men as human beings, though psychological and physiological differences are accepted.

\section{2-2-3- critical thinking}

Alexander (2006) believes that the attitude of democratic person toward authority is critical rather than deferential. A modern mind related to a critical thinking. Analyzing and evaluating everything in a rational way is the key point of critical thinking. Unlike the traditional people, modernists are active and not used to accept words without arguing. "Critical thinking" is a skill which should be learned.

\section{2-2-4- Individualism}

In this paper individualism is the fourth dimension of modernist sociopolitical attitudes. Modern person want more privacy and autonomy. An individual is any particular, the criterion of which is that it can be sorted, enumerated and picked out from the background. Individual may be abstract or actual. Individuals are 'historical occurrences, material objects, peoples and their shadows and all particulars; whereas qualities and properties, numbers and species are not' (Strawson, 1959: 15). Philosophically the most significant change occurred at the beginning of the Enlightenment with Descartes's first-person examination of the self. His famous claim that ' I think therefore I am' centers the individual and makes the mind transparent to itself. Thus Augustine's claim that ' I have become a question to myself' becomes, ' I can answer that question for myself by internal reflection upon myself' (Barry Clarke and Foweraker, 2001: 438-439). Historically, individualism and democracy have gone hand in hand but it does not follow from this historical tie that they are logically tied together. Then, Barry Clarke and Foweraker (2001) ask this question; is it possible for there to be a non-individualistic democracy? On the face of it the answer would seem to be pessimistic and negative. Democracy takes the individual as its core value. It does seem as if democracy that denied the value of individuals would be a contradiction in terms.

\section{2-3-sensation seeking and modernist socio-political attitudes}

Sensation seeking is a personality trait. The sensation seeking has been found to be positively correlated with risk taking behavior, a tendency to disclose personal thoughts and feelings, dislikes of structured and formal situations, adventure travel, a tendency to avoid repetition, a linking of intense experience, a proneness to boredom under restrained and repetitive situations, and a tendency toward disinhibition (LopezBonilla and Lopez-Bonilla,2010: 178-179). There is a positive association between sensation seeking and attraction to novel political and philosophical ideologies (Suranyi and et al, 2013: 274). People who have higher level of sensation have more tendencies to modern socio-political attitudes. They are more open-minded people. Michel et al. (1999) affirmed that the first theories of sensation seeking were based on the concept of "optimal stimulation level" where the people who seek sensation tend to reach a high level of stimulation. Sensation seeking scale (SSS) is composed of four dimensions: (a) experience seeking (ES), which represent the seeking of experience through the mind and senses, manifested as travel and nonconforming lifestyle; (b) boredom susceptibility (BS), representing an aversion to repetition and routine, and restlessness when things are not changing; (c) thrill and adventure seeking (TAS), expressed as a desire to engage in sports or other activities involving speed or danger, and (d) Dis, which represents the desire to be socially and sexually uninhibited (Lopez-Bonilla and Lopez-Bonilla,2010: 178). Theoretically sensation seekers should be good candidates for the adoption of new information technologies because they seek out novel experience. Some researchers believe that innovativeness is viewed as a personality trait reflecting a willingness to change (Lopez-Bonilla and LopezBonilla, 2012: 43). In fact, sensation seekers are more creative personality that leads them to new ideas and behaviors. That is why they are more interested in Internet and social media. On the internet they can find new friends and have new experiences which are not possible in the real world.

\section{2-4-Socio-economic status}

Income, education and job are the three main components of socioeconomic status. People who have achieved higher level of education has a different socio-political attitudes compare to those who have limited education (Guimond, 1999). Those who have a higher education have a higher frequency of a particular orientation. The more educated individual is more aware of the impact of government on the individual than is the person of less education. He is more likely to report that the follows politics and pays attention to election campaigns than is the person of less education. He has more political information. Ha has opinion on a wider range of political subjects; the focus of his attention to politics is wider. He is more likely to engage in political discussion. He feels free to discuss politics with a wider range of people. Those with less education are more wide range of subjects; and to engage in political discussions (Almond and Verba, 1989: 10). Parent's economic and social position also affects their attitudes toward political socialization of the children. People with different socioeconomic status behave in different ways with their children who are in sensation seekers. Parents in lower socioeconomic status try to limit and suppress their children's sensation seeking and parents with higher status 
try to lead this trait to more achievements for their children. So, according to these theories we can propose our hypotheses.

\section{2-5- Hypotheses and theoretical model} formulated:

Based on the theoretical framework and putting findings together, the following hypotheses are

Hypothesis 1: There is a significant relationship between the amount of sensation seeking and students' modernist socio-political attitudes

Hypothesis 2: There is a significant relationship between the socio-economic status and students' modernist socio-political attitudes.

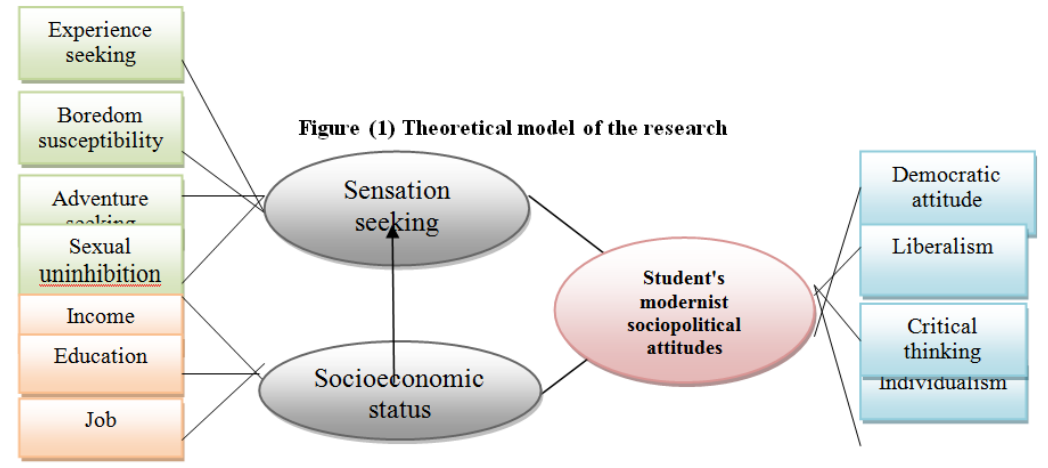

Figure (1) Theoretical model of the research

\section{Methodology}

This study performed by using survey method. The population of study consisted of all Isfahan University's students. The sample size was calculated based on the indices $\mathrm{t}=1.96, \mathrm{P}=0.6$ and $\mathrm{q}=0.4 \mathrm{using}$ Cochran's formula. Finally, a number of 360 students were selected as the participants using quota sampling method. In some of the scales, a number of questions were deleted to provide an acceptable value of alpha.

\section{3-1- Definition of the key concepts \\ Dependant variable}

\section{- Modernist Socio-political attitudes (MSPA)}

(MSPA) refer to a general tendency based on beliefs about sociopolitical issues like democracy, freedom, critical thinking, and individualism. The dimensions of MSPA including (1) democratic attitudes, (2) liberalism, (3) critical thinking, and (4) individualism. Scale of MSPA was made of 29 questions. After 2 questions were deleted, reliability coefficient reached to 8.7. Higher scores showed higher modern attitudes of students.

\section{Independent variable}

- sensation seeking

According to the latest definition of sensation seeking by Zukerman (1994) this is "a trait defined by the seeking of varied, novel and complex experiences, and the willingness to take physical, social, legal and financial risks for the sake of such experience". Sensation seeking scale (SSS) is composed of four dimensions: (a) experience seeking (b) boredom susceptibility (c) adventure seeking and (d) social and sexual uninhibition (Lopez-Bonilla and Lopez-Bonilla, 2010: 178).

- Socio-economic status

In our research socioeconomic status is composed of family income, the level of one's education, the level of one's father education, the level of one's mother education, the level of one's spouse education and one's job. To find out the position of students we also ask a direct question that what do they think about the position they have in the socioeconomic status.

\section{3-2- Reliability and validity of the questionnaire}

Face validity of questionnaire was determined by expert's viewpoint. For measuring the reliability of the scales (modernist sociopolitical attitudes, sensation seeking and socioeconomic status), Cronbach's alpha coefficient was calculated. In some of the scales, a number of questions were deleted to provide an acceptable value of alpha. The minimum acceptable alpha coefficient was considered to be 0.70 in order to confirm the reliability of the variables. 
Table 1. Validity and reliability of the scales

\begin{tabular}{|l|c|}
\hline \multicolumn{1}{|c|}{ variable } & Cronbach's alpha coefficient \\
\hline Modrnist Attitudes & $0 / 87$ \\
Democratic attitudes & $0 / 77$ \\
Liberalism & $0 / 81$ \\
Critical thinking & $0 / 67$ \\
Individualism & $0 / 59$ \\
Sensation seeking & $0 / 63$ \\
Socioeconomic status & $0 / 71$ \\
\hline
\end{tabular}

\section{3-3- statistical Findings}

Table 2 shows that the highest total percentage (33.6) of student's modernist sociopolitical attitudes (SMSPA) belongs to the 'medium' and the high levels and the lowest percentage (32.8) belongs to the low level. That means most of the Isfahan University's students have modern attitudes.

Table 2: sample distribution and percentage of student's modernist sociopolitical attitudes

\begin{tabular}{|c|c|c|}
\hline & distribution & percentage \\
\hline Low & 118 & 32.8 \\
\hline Medium & 121 & 33.6 \\
\hline High & 121 & 33.6 \\
\hline Total sum & 360 & 100 \\
\hline
\end{tabular}

Table 3 shows that the highest total percentage (37.8) of sensation seeking belongs to the' high' level and the lowest percentage (29.1) belongs to the medium level. 119 students (33.1) have low level of sensation seeking. That means most of the Isfahan University's students are sensation seekers.

Table 3: sample distribution and percentage of the amount of sensation seeking

\begin{tabular}{|c|c|c|}
\hline & distribution & percentage \\
\hline Low & 119 & 33.1 \\
\hline Medium & 105 & 29.1 \\
\hline High & 136 & 37.8 \\
\hline Total sum & 360 & 100 \\
\hline
\end{tabular}

This table shows that the highest total percentage (69.2) of student's socioeconomic status belongs to the' medium' level and the lowest percentage (3.3) belongs to the high level. 99 students (27.5) have low position of socioeconomic status. That means most of the Isfahan University's students have medium position of socioeconomic status.

Table 4: sample distribution and percentage of socioeconomic status

\begin{tabular}{|c|c|c|}
\hline & distribution & percentage \\
\hline Low & 99 & 27.5 \\
\hline Medium & 249 & 69.2 \\
\hline High & 12 & 3.3 \\
\hline Total sum & 360 & 100 \\
\hline
\end{tabular}

\section{3-4- Inferential Findings}

Here, the research hypotheses are tested, and varying statistical tests are being used based on the type of variables. Because the distribution of variables are not normal so, we use Spearman's rho coefficient. Table 5 shows the correlation between amount of sensation seeking and (SMSPA). As the Spearman's rho coefficient $(0.188)$ with $(\mathrm{sig}=0 / 000)$ showed there is a significant correlation between these two variables.

Table 5: Correlation between sensation seeking and student's modernist sociopolitical attitudes

\begin{tabular}{ccc}
\hline \multicolumn{3}{c}{ The rate of sensation seeking } \\
\hline sig. & $\begin{array}{c}\text { Spearman's rho } \\
\text { coefficient }\end{array}$ \\
\hline $0 / 000$ & $0 / 188$ & $\begin{array}{c}\text { Modernist sociopolitical } \\
\text { attitudes }\end{array}$ \\
\hline
\end{tabular}

Table 6 shows the correlation between socioeconomic and (SMSPA). A significant correlation was observed between these two variables. The Spearman's rho coefficient $(0.234)$ with $(\mathrm{sig}=0 / 000)$. 
Student's modernist socio - political attitudes and Sensation seeking (The case of study: Isfahan

Table 6: Correlation between socioeconomic status and student's modernist sociopolitical attitudes

\begin{tabular}{ccc}
\hline & Socioeconomic & \\
\hline sig. & $\begin{array}{c}\text { Spearman's rho } \\
\text { coefficient }\end{array}$ & \\
\hline $0 / 000$ & $0 / 234$ & $\begin{array}{c}\text { Modernist sociopolitical } \\
\text { attitudes }\end{array}$ \\
\hline
\end{tabular}

\section{3-5-Multivariate analysis}

To calculate this analysis we used the enter method in which we enter all the independent variables into the analysis then the effects of them on dependant variable analyzed.

Table 7: Multivariate analysis in a Enter method

\begin{tabular}{|c|c|c|c|c|c|}
\hline \multirow[b]{2}{*}{ Sig. } & \multirow[b]{2}{*}{$\mathbf{t}$} & \multirow{2}{*}{$\frac{\text { Standardized coefficient }}{\text { Beta }}$} & \multicolumn{2}{|c|}{ Unstandardized coefficient } & \multirow{2}{*}{ Independent variables } \\
\hline & & & Std. Error & $\mathrm{B}$ & \\
\hline 000 & $6 / 380$ & $0 / 320$ & $0 / 142$ & $0 / 903$ & Sensation seeking \\
\hline $0 / 150$ & $1 / 442$ & $0 / 072$ & $0 / 107$ & $0 / 154$ & Sociopolitical status \\
\hline
\end{tabular}

In table 7 with a enter method and multivariate regression, the dependent variable is being dealt with. As it can be see sensation seeking has accounted for 0.320 Beta standardized coefficient with (sig $=000$ ) of the dependent variable, but socioeconomic status has not accounted. Beta value shows that the relationship between sensation seeking has a positive relationship with the dependant variable. $R$ square values $0 / 113$. This value shows the percentage of changes of the dependant variable by independent variables.

\section{3-6-The structural equation modeling}

To test the theoretical model and research's hypotheses we used structural equation modeling. We preferred structural equation modeling framework because it provides the researchers with tools to test the fit of the model to the data and directly test the significance effects (Kline, 2005). In the tested model, (MSPA), sensation seeking and sociopolitical status are latent variables. Model fit indices such as CMIN/DF ratio, IFI, NFI, CFI, PCFI, RMSEA, were inspected.

\section{Figure (2) standardized coefficient of structural equation modeling}

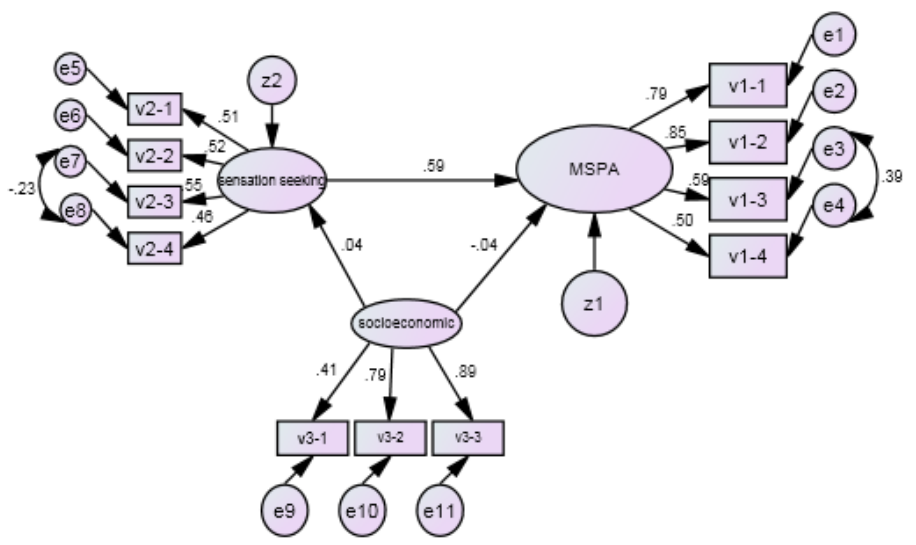

As table 8 shows the fit indices of the model show that it has goodness of fit. Since RMSEA value is smaller than 0.08 and NFI value is 0.87 and close to 1 , we can confirm the developed model. Other indices such as Incremental fit index IFI and CFI values were larger than 0.9. Thus, the developed model has goodness of fit and is supported by the data obtained from the population. The t-value of all standardized coefficients in the model were larger than 1.96. Therefore, all standardized coefficients written on the arrows are significant.

Table 8: model fit indices and information criteria values for the model

\begin{tabular}{|c|c|c|c|c|c|c|c|}
\hline Indices & df & CMIN/df & CFI & IFI & NFI & PCFI & RMSEA \\
\hline Value & 49 & $2 / 797$ & $0 / 915$ & $0 / 917$ & $0 / 876$ & $0 / 680$ & $0 / 071$ \\
\hline
\end{tabular}




\section{Discussion and conclusion}

This study aimed to investigate modernist sociopolitical attitudes among students and the effect of the sensation seeking and socioeconomic status variables on it: a case study in Isfahan University. Iran's society particularly Iranian students have been changing. Their attitudes toward modernity and sociopolitical issues have been changed. Unlike the past, the amounts of individuality and willingness to freedom of express among people have been increased. As the result shows, most of the students in research's population have modern sociopolitical attitudes. The result of statistical findings show that the highest total percentage (33.6) of SMSPA belongs to the 'medium' and the high level and the lowest percentage (32.8) belongs to the low level. That means most of the Isfahan University's students have modern attitudes. And about the sensation seeking, the highest total percentage (37.8) of this variable belongs to the' high' level and the lowest percentage (29.1) belongs to the medium level. 119 students (33.1) have low level of sensation seeking. That means most of the Isfahan University's students are sensation seekers. The result also shows that the highest total percentage (69.2) of student's socioeconomic status belongs to the' medium' level and the lowest percentage (3.3) belongs to the high level. 99 students (27.5) have low position of socioeconomic status. That means most of the Isfahan University's students have medium position of socioeconomic status.

In the theoretical framework upon the theories we proposed two main hypotheses: 1- There is a significant relationship between the amount of sensation seeking and SMSP. 2: There is a significant relationship between the socio-economic status and SMSPA. The result of a two-variate regression shows that there is a positive relationship between the two independent variables (sensation seeking and sociopolitical status) and SMSPA. Spearman's rho coefficient $(0.188)$ with $(\mathrm{sig}=0 / 000)$ showed there is a significant correlation between sensation seeking and SMSPA. Also, a significant correlation was observed between socioeconomic status and SMSPA. The Spearman's rho coefficient was $(0.234)$ with $(\mathrm{sig}=0 / 000)$. So, both hypotheses are confirmed. In the other words, as the amount of sensation seeking and socioeconomic status increase, the amount of SMSPA also increases. The result of multivariate analysis shows that there is significant correlation between sensation seeking and SMSPA. Beta standardized coefficient is 0.320 with $(\mathrm{sig}=000)$. The value of $\mathrm{R}$ square shows that independent variables account for 0/113 of changes in SMSPA. The result of the fit indices of the structural equation modeling shows that, the model has goodness of fit. Model fit indices such as CMIN/DF ratio, IFI, NFI, CFI, PCFI, RMSEA, were inspected. RMSEA value was smaller than 0.08 and NFI value was 0.87 and close to 1 . Other indices such as Incremental fit index IFI and CFI values were larger than 0.9. Thus, the developed model has goodness of fit and is supported by the data obtained from the population.

Suranyi and et al (2013) also argued that there is a positive association between sensation seeking and attraction to novel political and philosophical ideologies. This study in its type was almost new (particularly in Iran) thus, to find out more about the effects of personal traits on sociopolitical attitudes we need more studies. In new studies it would be a good idea to apply qualitative research along the quantitive research. Because attitude has complicated and different aspects which to be clarified needs the complicated methods.

\section{References}

[1]. Adorno, T.Wm Frenkel-Brunswik,E., Levinson, D.J, and Stanford, R.N (1950), The authoritarian personality. New York. Harper.

[2]. Ajzen, Icek (2001), Nature and operation of attitudes. Annual Reviews. Psycho.52:27-58.

[3]. Almond, Sidney and verba, Gabriel A (1989), civic culture political attitudes and democracy in five nations. Sage publication.

[4]. Baumeister, Roy F and Finkel, Eli J (2010), Advanced social psychology The state of the science, Oxford university press.

[5]. Alexander, Jeffrey C. (2006), The civil sphere, Oxford university press.

[6]. Barry Clarke, Paul, and Fowerker Joe (2001), Encyclopedia of democratic thought, published by Routledge, London.

[7]. Blee, K.M., and Tickamyer, A (1995), Racial differences in men's attitudes about women's gender roles. Journal of marriage and family, 57, 21-30.

[8]. Guimond, S. (1999), Attitude change during college: normative or informational social influence? Social psychology of Education, $2,237-261$.

[9]. Hastie, B. (2007). Higher education and sociopolitical orientation: The role of social influence in the liberalization of students, European journal of psychology of Education, 3. $259-274$.

[10]. Kellner, Douglas (1995), Media culture. Cultural studies, identity and politics between the modern and the postmodern. New York and London: Routledge.

[11]. Lopez-Bonilla, Jesus Manual and Lopez-Bonilla Luis Miguel (2009), sensation-seeking and the use of the internet, sage publication.

[12]. Luther, Timothy C. (2009), Hegels critique of modernity reconciling individual freedom and the community, United Kingdom, Lexington Books.

[13]. Martin, J, G., and Westie, E. R. (1959), The tolerant personality, American sociological review, 24, $521-528$.

[14]. Oskamp, Stuart and Schultz, Wesley P (2005), Attitude and opinion, Third addition, Lawrence Erlbaum Associates, publishers Mahava, New jersey.

[15]. Kline, R. B. (2005), principles and practice of structural equation modeling. New York: Guildford.

[16]. Strawson, P.F. (1959), Individuals: an essay in descriptive metaphysics, London: Methuen.

[17]. Suuranyi, Zsuzanna and Hitchcock, David B and et al (2013), Different types of sensation seeking: A person - oriented approach in sensation-seeking research, sage publication.

[18]. Tetlock, P. E. (1983), Policy-makers images of international conflict, Journal social issues, 39 (1), 67-86. 